\title{
The Enduring Discoveries of Generative Syntax
}

\author{
LISA LAI-SHEN CHENG ${ }^{1}$ AND JAMES GRIFFITHS ${ }^{2}$ \\ ${ }^{1}$ Leiden University, Leiden, Netherlands \\ ${ }^{2}$ University of Tübingen, Tübingen, Germany
}

\subsection{Introduction}

We suspect that those interested in the enduring discoveries of generative syntax wish to read about empirically supported assertions about natural language syntax advanced by generative linguists (discoveries) that are currently not disproven and that are still routinely mentioned in the generative syntax literature, usually as a diagnostic tool (enduring). Acting on this suspicion, our discussion in this chapter is restricted to assertions that fit this description. Because constraints on space require us to be selective, and in order to maintain thematic alignment with other chapters in this volume, we limit our presentation to those enduring discoveries that we consider to be indisputably generative in character, insofar as they are a natural and conspicuous product of the research methodology engendered by Chomsky's philosophical commitments and his general vision for linguistic research. ${ }^{1}$ We begin by discussing how the two main goals of generative research, which were cemented in Chomsky's earliest writings, yield a practical research methodology that allows for the rapid accumulation of new linguistic data and knowledge; a methodology that early adopters exploited to make many of the field's enduring discoveries (Section 4.2). We then discuss how, by introducing the linguistic community to generativism via his transformational theory, Chomsky fixed early research attention on nonlocal dependencies, about which many of the field's enduring discoveries are concerned (Section 4.3). Section 4.3.1 discusses the enduring discoveries made about the hierarchical syntactic structures on which nonlocal dependencies are instantiated, Section 4.3.2 reflects on the variety of nonlocal dependencies that generative research has uncovered, and Section 4.3.3 focuses on so-called gaps or empty categories, which frequently feature as members in nonlocal dependencies. We provide concluding remarks in Section 4.4. 


\subsection{Shaping the Research Methodology of Generative Linguistics}

It is universally accepted that the progress made by generative linguists since the late 1950s represents a significant leap in our understanding of natural language syntax. The powerful methodology wielded by generative linguists played - and continues to play - a hugely important role in this rapid advancement. In this section, we describe how the core principles of generative linguistics, which were outlined by Chomsky in the 1950s and 1960s, yielded a research methodology whose core features guarantee quick and fruitful syntactic research.

The founding dictum of generative linguistics is that linguists should study grammars, where a grammar of a particular language L is understood as a set of rules for generating the sentences that constitute L (Chomsky 1955 et seq.). From the late 1950s onward, Chomskyan generative grammar has also adopted a rationalist conception of language (Chomsky 1958, 1959), according to which "a grammar of a particular language must be supplemented by a universal grammar [our emphasis] that accommodates the creative aspect of language use and expresses the deep-seated regularities which, being universal, are omitted from the grammar itself" (Chomsky 1965, 6). This engenders a linguistic research program with two main goals: I. to specify the rules that generate all and only the grammatical sentences in a given language $\mathrm{L}$ (we return to the concept of grammaticality momentarily), and II. to determine which of these rules belong to the universal grammar and which are specific to $\mathrm{L}$.

These two goals are directly reflected in the research methodology employed by generative linguists from the 1950s until today. The first goal is reflected in the choice of data-type used for generative linguistic research, while the second is reflected in the methodological outlook adopted by generative researchers.

To accomplish goal I., a linguist will (ideally): (i) hypothesize a grammar for L and then (ii) test to see if it correctly generates all and only the grammatical sentences in L. To successfully carry out this test, a linguist must know beforehand the grammatical status of sentences through an independent test to avoid introducing circularity into the methodology described above. This independent test comes from acceptability judgments. Acceptability judgments are reports provided by a native speaker of their spontaneous reaction concerning whether a particular string of words (with an intended interpretation) is a possible sentence of their language. Generative linguistics has used acceptability judgments as its primary data source since its inception (Chomsky 1955, 1957), treating these judgments as a valid and valuable source of information about the grammaticality of a sentence. In other words, generative linguistics has always assumed that the reaction triggered by exposure to a candidate sentence of one's native language can help determine whether the sentence can or cannot be generated by that language's grammar. ${ }^{2}$ In addition to this tacit acceptance of acceptability judgments as a valid data-source, Aspects of the theory of syntax (1965), Chomsky's most cited book on linguistics, explicitly defended their use, arguing that no adequate alternative method of probing linguistic competence was available (at the time) or would likely be discovered, and that, on the off-chance that an alternative method was developed, acceptability judgments will still be required as a benchmark against which to test the alternative method's efficacy (p. 18-21). Chomsky therefore highlights that acceptability judgments are the most easily obtained source of ungrammatical sentences, which 
are indispensable for conducting the everyday task of generative research, namely developing accurate characterizations of grammars. ${ }^{3}$

Accomplishing the second main goal of generative linguistic research has been regularly delayed by Chomsky's periodic refinement or revision of his conception of the universal grammar and its relation to language-specific grammars (Chomsky 1970, 1977, 1981, 1986b, 1995). Despite periodic conceptual changes, the methodological outlook used for pursuing this goal has remained constant. One aspect of this outlook is the adoption of a working method in which productive patterns observed in one language are presumed to be present in all languages until empirical evidence proves otherwise. Because discovering the properties of the universal grammar is more pressing than discovering the rules of the ancillary language-specific grammar from a rationalist perspective such as Chomsky's (as the universal grammar is innate whereas the language-specific grammar is learned), another aspect of this outlook is its focus on linguistic regularities, or "core language" (Chomsky 1986a, 147).

In sum, the theoretical commitments emplaced by Chomsky in the late $1950 \mathrm{~s}$ and early 1960s engendered a research methodology in which informally collected acceptability judgments are used to make generalizations over linguistic regularities. Considering that acceptability judgments are reliable, relatively unequivocal (see the references in endnote 3), and are quickly obtained (especially if a linguist is collecting judgments from herself and/or a small group of consultants), and that the rationalist principles underpinning the generative paradigm has given linguists warrant to make universal claims from studying one language that they know well (usually their native tongue), it is unsurprising that this methodology yields new data, generalizations, and analyses at an extremely rapid rate. Equally, it is unsurprising that its initial application in the early days of generativist syntax to what was then an uncharted empirical landscape of syntactic regularities resulted in most of the profound - and therefore the most enduring - discoveries of generative syntax.

\subsection{Generative Syntax Through the Lens of Nonlocal Dependencies}

Although generative linguistics is predominantly a syntax-focused program (see Jackendoff 2002 for criticism of this fact), the methodology described in the previous section is intended for use in all linguistic subfields (see Chomsky and Halle 1968 for a famous application of the methodology to phonology). Its enduring association with syntactic research stems from the fact that Chomsky first employed the methodology to study the regularities of English syntax in Syntactic Structures (1957). In addition, Syntactic Structures also set the research agenda for precisely which syntactic regularities linguists would focus on in the early period (the 1960s and 1970s) of generative theorizing. From a broad, theory-neutral perspective, the regularities in question can each be described as instantiating a nonlocal dependency. One example of a nonlocal dependency is the relationship that obtains between every Englishman and his in (1): the specification for his depends on the specification for every Englishman (i.e. Gerald takes pride in Gerald's garden, Norman takes pride in Norman's garden, etc.), even though these phrases are separated by the string of words takes pride in.

(1) Every Englishman takes pride in his garden. 
This concrete notion of a nonlocal dependency can be extended to include a slightly more abstract case, such as the dependency into which the nominal expression the cake enters in (3). In (2), this expression occupies a position immediately following the verb. Because this position is the designated object position in English, the cake is understood as the sentence's object, i.e. the thing being eaten. In (3), however, the cake is still understood as the object of the sentence, despite being separated from the position immediately following the verb by two words (namely, was and eaten). In this configuration, one may characterize the cake as entering into a nonlocal dependency with the position immediately following the verb, which is represented by the symbol " $\Delta$ " in (3) and is known as the gap (or an empty category).

\section{(2) Ashley ate the cake.}

(3) The cake was eaten $\Delta$ by Ashley.

Influenced by ideas developed by Harris (1952, 1957), Chomsky in Syntactic Structures (1957) introduced the idea that certain sentences are derived from other sentences via rewrite rules over phrase markers (a special type of derivation tree whose termini are adorned with the atoms of syntactic analysis, namely words and morphemes), which he called transformations. One such transformation is the passive transformation, which converts the phrase marker for an active sentence such as (2) into its passive counterpart in (3). Although Chomsky did not originally view the output of a transformation as instantiating a nonlocal dependency, ${ }^{4}$ the way in which his transformational analysis focused generative linguists' attention on nonlocal dependencies from the outset of the generativist enterprise is clear, as transformations suggest that some nonlocal connection - in this case, a derivational history - obtains between the two positions of the cake in (2) and (3). This early focus on nonlocal dependencies and the constraints on establishing them produced many of the early enduring discoveries of generative syntax.

In the remainder of this section, which constitutes the main body of our overview, we first outline some of the enduring discoveries made about the syntactic structures that serve as the scaffolding for nonlocal dependencies (Section 4.3.1), before turning our attention to enduring discoveries made about nonlocal dependencies themselves (Section 4.3.2). It will become clear from the discussions in these sections that natural language contains many gaps (also known as empty categories): Section 4.3.3 discusses the variety of gaps that generative linguists have uncovered.

\subsubsection{Nonlocal Dependencies and Hierarchical Structure}

The discovery that the establishment of a nonlocal dependency rests on hierarchical relations between words and phrases rather than on linear relations represents a watershed moment for generative syntax. This discovery was first documented by Klima (1964), who introduced the notion of in-construction-with (p. 297), whose converse was rebranded as c-command by Reinhart (1976). C-command is defined over nodes in a phrase marker. According to Reinhart's definition (p. 32), a node A c-commands a node $\mathrm{B}$ if and only if the first non-unary node that dominates $\mathrm{A}$ (call it $\mathrm{C}$ ) also dominates B (see (4)). (Aside from A, B, and C, the labels decorating the nodes in (4) and (6) are arbitrarily assigned.) 
(4)

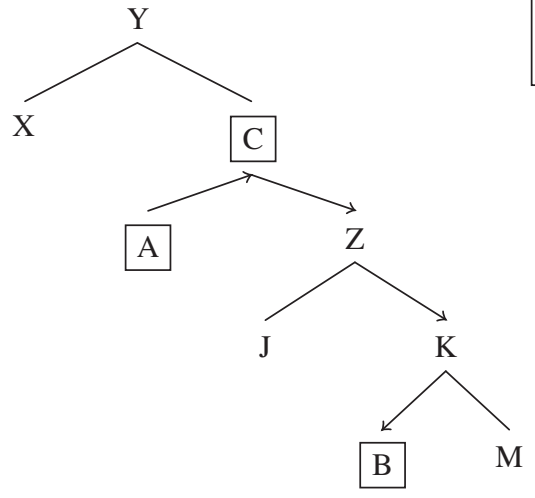

A c-commands B

(where the arrows show the path of c-command from A to B)

The fact that nonlocal dependencies rest on c-command is illustrated in the following sentences. Any in (5a) is a negative polarity item (NPI), whose use must be "licensed" by it entering into a dependency relation with a negative item such as nobody (in (5b), any is not permitted because nobody is absent; Klima 1964). Although it might seem from comparing (5a) and (5c) that nobody must merely linearly precede any for a dependency to be established between them, (5d) shows that an appeal to linearity alone is insufficient, as nobody linearly precedes any yet the sentence is unacceptable. The crucial insight here is that nobody also c-commands any in (5a) (transposed onto (4), nobody occupies A's position and any occupies B's position), whereas nobody does not c-command any in (5d), as (6) shows. This insight not only refined ideas about syntactic dependencies, but also conclusively demonstrates that natural language syntax is sensitive to hierarchical structure: it is a two-dimensional phenomenon. Thus, the discovery of c-command underscores the notion, which is implied in Chomsky's (1957) pioneering use of phrase markers, that syntactic relations between words/morphemes are predominantly (and perhaps exclusively; see Kayne 1994) hierarchical in nature, and that linear order is, perhaps counterintuitively, largely irrelevant to natural language syntax.

(5) a. Nobody thinks that Harriet wants any wine.

b. * Somebody thinks that Harriet wants any wine. ${ }^{5}$

c. * Any wine is wanted by nobody.

d. * That nobody bought beer means we must drink any wine.

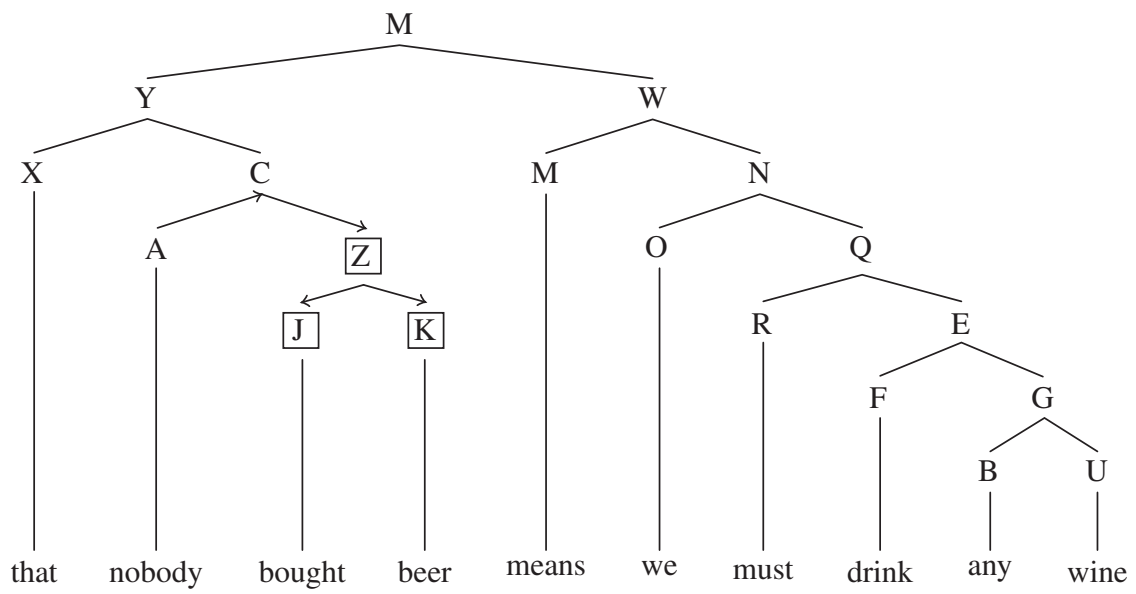


A c-commands each boxed node, which does not include B. Therefore, a nonlocal dependency between nobody and any cannot be established.

Our understanding of the hierarchical structure on which nonlocal dependencies are instantiated has undergone substantial refinement since Chomsky's (1957) pioneering use of phrase marker diagrams. From Syntactic Structures until the mid-1970s, words from lexical categories (e.g. nouns and verbs) and functional categories (e.g. articles such as the and auxiliary verbs) were treated dissimilarly with respect to syntactic structure. Lexical words were usually analyzed as heads of syntactic phrases (where a head of a phrase determines the phrase's category), whereas functional words were not. To provide an example, the noun (N) dog in (7) is the head of the noun phrase (NP), but the determiner (D) the is not the head of a determiner phrase. Instead, it is contained in the noun phrase.

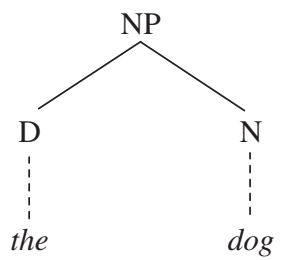

Building on results obtained from the mid-1970s through to the mid-1980s (in particular, Emonds 1976, Jackendoff 1977, Fukui 1986, Speas 1986, and Abney 1987), Chomsky's (1986b) Generalized $X^{\prime}$-theory abandoned the notion that lexical and functional words are structurally distinct. Instead, functional words behave just like lexical ones: they are heads of syntactic phrases (a determiner will 'project' a determiner phrase (DP), for instance (8)). ${ }^{6}$

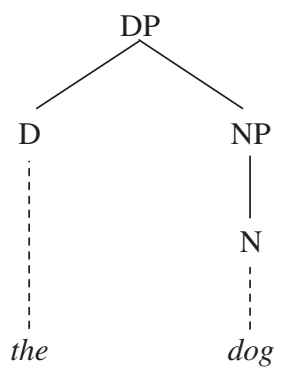

The distinction between lexical and functional items has a long tradition in linguistics. Consequently, the discovery that lexical and functional words are structurally equivalent (insofar as both project phrases) has endured because it eliminated a potential source for this distinction and therefore stimulated much research into precisely where, if not in terms of projecting phrases, the difference between lexical and functional items lies. Grimshaw (2000 [1991]) discovered that the crucial difference can be found in the respective ordering of lexical and functional phrases: lexical phrases are always dominated by functional ones. Moreover, there is a constrained pairing between lexical and functional phrases, with functional phrases acting as the extended 
projections of the lexical phrases they dominate. For instance, the extended projections of lexical $\mathrm{N}$ are the projections of functional $\mathrm{D}$, and these share the same categorial features with $\mathrm{N}$ (e.g. nominal).

Grimshaw's work in turn stimulated much research into the precise make-up of various extended projections. Certain conclusions reached in this subfield can already be viewed as "enduring discoveries," based on the weight of evidence marshalled to support them and for their utility as diagnostics of other syntactic properties. An instructive example comes from how verbs project syntactic structure. Researchers recognized that, instead of having functional projections related to tense and aspect as the immediate extended projections of $\mathrm{V}$ (as in Grimshaw's original system), $\mathrm{V}$ is immediately dominated by (at least) one functional projection that relates to the internal thematic/eventive meaning of $\mathrm{V}$. The head of this projection, which is referred to as " $v$ " by Chomsky (1995), is broadly identified as the syntax reflex of agentivity or causation, as it selects the external argument (i.e. the agent) of an event (Larson 1988; Hale and Keyser 1991, 1993; Krazter 1994; Chomsky 1995, 2000) (9).

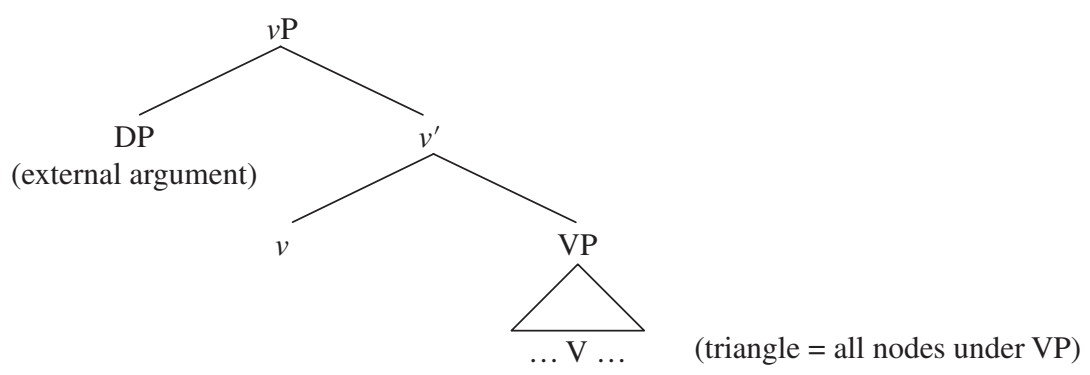

Support for the existence of $v$ comes from the fact that its presence explains two independent enduring discoveries. The first concerns the discovery from Perlmutter (1978) that two classes of intransitive verbs - namely, unergative and unaccusative verbs - can each be associated with different syntactic phrase markers. Despite their surface similarities, unergatives have an underlying subject while unaccusatives have an underlying object. A natural structural explanation for this distinction is that unaccusative verbs have no vP projection (though see Alexiadou, Anagnostopoulou, and Everaert 2004). The second enduring discovery comes from Burzio (1981), who observed that a verb can assign a thematic role (e.g. the agent, experiencer, source, etc., of an event) to its subject if and only if its object can receive accusative case. This is Burzio's generalization. If the functional head $v$ is responsible for introducing the subject and assigning accusative Case to object DPs, then if $v$ is missing, then Burzio's generalization is explained.

In summary, generative research has underscored the importance of syntactic hierarchy in encoding traditional linguistic distinctions (e.g. lexical versus functional), encoding compositional meaning (e.g. agentivity), and establishing dependencies between words and/or phrases.

\subsubsection{A Typology of Nonlocal Dependencies}

While generative linguists found a universal constraint on nonlocal dependencies in c-command (see 4.3.1), other constraints that were unearthed - and which are enduring discoveries in their own right - were observed to apply to some nonlocal 
dependencies but not others. It was quickly demonstrated that, for any nonlocal dependency $\mathrm{D}$, the syntactic type of the elements involved in the dependency, whether the dependency includes a gap or not (recall (1) versus (3)), and the syntactic position occupied by the top member of the dependency can each determine what constraints are emplaced on successfully establishing D in the first place.

For instance, dependencies between syntactic heads of phrases (e.g. (10)) are more constrained than dependencies between syntactic phrases themselves, as the former can only be established across a very short structural distance (two structurally consecutive syntactic heads; Travis 1984), whereas certain dependencies between syntactic phrases can be unbounded. With regards to dependencies between phrases, those involving gaps as tail members typically cannot be established if the gap is contained in one of a handful of distinguished phrases known as islands (Ross 1967), whereas those without gaps are typically untroubled by islands (compare (11) and (12), with an "adjunct island" headed by because). Therefore, the status of a dependency's tail also determines across what distance the dependency can be established.

(10) Will Polly $\Delta$ be attending the party?

(11) Every auntie thought that baby Bobby smiled [ISLAND because she had just arrived].

* I know who baby Bobby smiled [ISLAND because $\Delta$ had just arrived].

When there are no syntactic islands present in a sentence, it appears at first glance that the distance across which a dependency with a phrasal tail gap can be established is unrestricted. In the sentences in (13), for instance, the apparent tops and tails of each dependency occupy different clauses, and the dependencies themselves extend across multiple clausal boundaries (which are denoted by $\mathrm{C} 1, \mathrm{C} 2$, and C3).

(13) a. Xavier seems [ ${ }_{\mathrm{C} 1}$ to appear [ ${ }_{\mathrm{C} 2}$ to want [ ${ }_{\mathrm{C} 3}$ to be hired $\Delta$ by Sue $\left.]\right]$.

b. Who does Bo think [ $\left[_{\mathrm{C} 1}\right.$ Zoë hopes $\left[{ }_{\mathrm{C} 2}\right.$ Jo believes $\left[{ }_{\mathrm{C} 3}\right.$ that Sue hired $\left.\left.\left.\Delta\right]\right]\right]$ ?

Another enduring result of generative syntax research has been to show that, in these cases, appearances are deceptive. In reality, nonlocal dependencies of this type cannot extend across more than one finite clausal boundary. ${ }^{7}$ Thus, the sentences in (13) actually contain multiple dependencies, none of which extend across more than one clausal boundary, as illustrated in (14). The presence of each dependency in (14a,b) - a number of which consist entirely of gaps and therefore appear as "hidden" dependencies - can be confirmed through following the generative methodology outlined in Section 4.3.1: i.e. by applying syntactic tests known to diagnose the presence of such hidden dependencies and by showing that visible versions of these dependencies are attested in other languages (Frisian: Hiemstra 1986, German and Romani: McDaniel 1989; Chamorro: Chung 1994; Irish: McCloskey 2001; among many others). In certain dialects of German, for instance, the intermediate gaps in (14b) are replaced by question words, as (15) shows.

(a) Xavier seems [ ${ }_{1} \Delta_{1}$ to appear [ ${ }^{2} \Delta_{2}$ to want [ ${ }^{3} \Delta_{3}$ to be hired $\Delta_{4}$ by Sue]]].

(b) Who do you believe [ ${ }_{\mathrm{C} 1} \Delta_{1}$ Peter thinks [ ${ }_{\mathrm{C} 2} \Delta_{2}$ Sue is marrying $\left.\left.\Delta_{3}\right]\right]$ ? 
(15) Wen glaubst du wen Peter meint wen Susi heiratet? (Felser 2004 (10)) who believe you who Peter thinks who Susi marries

'Who do you believe Peter thinks that Susi is marrying?'

We previously mentioned that the structural position occupied by the top member of a dependency may determine the syntactic properties of that dependency. This is especially noticeable for dependencies between phrases with gaps as their tail members. In such cases, a correlation exists between the structural position occupied by the top member of the dependency - whether it occupies an argument position (an A-dependency), such as the syntactic positions reserved for subjects and objects, or a non-argument position (an $A^{\prime}$-dependency) - and how the dependency interacts with other grammatical phenomena. If a nominal expression that refers to the same person or thing as the top member of a dependency D intervenes between the top and tail members of D, D is licit if it is an A-dependency but illicit if it is an $\mathrm{A}^{\prime}$-dependency (this is a crossover effect; Postal 1971) (compare (16a) and (16b)). A- and $A^{\prime}$-dependencies differ in other ways, too. $A^{\prime}$ but not A-dependencies can license the presence of parasitic gaps (compare (17a) and (17b), where " $\Delta_{\mathrm{P}}$ " represents a parasitic gap) (Ross 1967, Engdahl 1983), and the top member of an A-dependency can also be the tail member of an $\mathrm{A}^{\prime}$-dependency, but not vice versa (compare (18a) and (18b)) (Chomsky 1973). Their behavior also differs with respect to reconstruction (May 1977, Chomsky 1977, van Riemsdijk and Williams 1981; see Barss 2001 for an overview), a pervasive linguistic phenomenon to which we return in Section 4.3.4.

(16) a. Fiona seems to her mother $\Delta$ to be a genius. (acceptable when Fiona and her are interpreted as referring to the same person)

b. * Who does her mother love $\Delta$ ? (unacceptable when who and her are interpreted as referring to the same person)

(17) a. This secret file should be burned $\Delta$ after reading $\left\{\right.$ it $\left./{ }^{*} \Delta_{\mathrm{P}}\right\}$.

b. Which secret file did the FBI agent burn $\Delta$ after reading $\left\{\right.$ it $\left./ \Delta_{\mathrm{P}}\right\}$ ?

(a) Who does Hans think $\Delta_{1}$ was fired $\Delta_{2}$ by Sue?

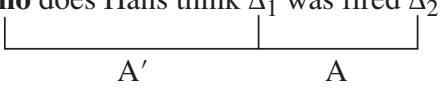

(b) $*$ Who is believed $\Delta_{1}$ that Sue hired $\Delta_{2}$ ?

A

$\mathrm{A}^{\prime}$

Having uncovered this rich empirical landscape of nonlocal dependencies with tail gaps, an obvious question that arose was this: For each type of dependency with a tail gap, is there a mirror version, whereby the top is a gap and the tail is an overt item? And if so, do these mirror versions display the same properties as the originals? Thanks to 
another handful of enduring discoveries, generative linguists have demonstrated that both questions must be answered with "yes." Although originally couched in the language of transformations, a "top-gap" dependency between heads was first postulated by Chomsky (1957) for English verbal inflection (19), and the universal presence of such dependencies in natural language has been confirmed by much succeeding research (see Adger, Harbour, and Watkins 2009; Harley 2013; and Harizanov and Gribanova 2018 for discussion).

(19) Polly $\Delta$ often eat-s raw carrots for breakfast.

In many languages, question phrases such as who, why, and which student do not occupy the sentence-initial position in a standard question - as in English - but instead occupy their typical position in non-question counterparts (e.g. the subject, object, or adverbial position). Such languages are known as wh-in-situ languages. Generative linguists discovered that question phrases in wh-in-situ languages instantiate top-gap $\mathrm{A}^{\prime}$-dependencies (see the Turkish example in (20)), in which the gap occupies a position high above the sentence, therefore allowing the question phrase, via its connection with the gap, to take logical scope over the entire sentence. The establishment of these top-gap dependencies is constrained in precisely the same manner as their tail-gap counterparts (see examples (11) and (12) and accompanying text). ${ }^{8}$ To see this clearly, compare the simplified phrase markers in (21). Putting irrelevant differences between these languages aside, one observes that their question-formation strategies are the same, differing only in which member of the $\mathrm{A}^{\prime}$-dependency is pronounced (i.e. top-gap in English vs. tail-gap in Turkish).

\section{$\Delta \quad$ Ayşe kim-i öp-tü?}

Ayşe who-Acc kiss-PST

'Who did Ayşe kiss?'
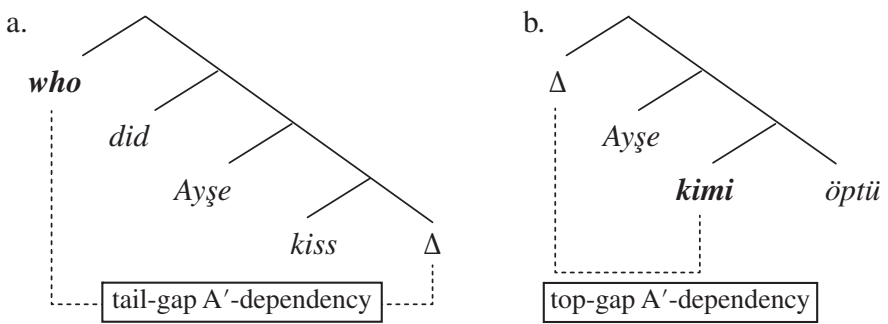

In addition, generative linguists have also discovered that some languages, such as Adyghe (a Northwest Caucasian language; see Potsdam and Polinsky 2012), utilize top-gap A-dependencies. In (22), the subject of root clause is an unpronounced gap, yet this gap co-refers with the demonstrative pronoun a-xe-me "these/they" in the embedded infinitival clause.

$$
\begin{aligned}
& \Delta \quad \text { [ a-xe-me pjəsme-r a-txə-new ] ø-fjež'a-ве-х } \\
& \text { DEM-PL-ERG letter-ABS 3PL.ERG-write-INF 3ABS-begin-PST-3PL.ABS }
\end{aligned}
$$

'They began to write a letter.' 
When neither the top nor the tail of a dependency D is a gap (and therefore both the top and the tail are overt items), in cases where the dependencies concern nominal expressions, the status of the tail often determines which constraints are emplaced on establishing D. ${ }^{9}$ For instance, the locality conditions on establishing the dependency vary according to whether the tail member is a personal or possessive pronoun (e.g. she, her) or a reflexive or reciprocal pronoun (e.g. herself, each other). Roughly speaking, a personal or possessive pronoun $\mathrm{P}$ can establish a syntactic dependency with a c-commanding nominal expression $\mathrm{N}$ only if $\mathrm{N}$ does not occupy P's binding domain (23), ${ }^{10}$ whereas a reflexive or reciprocal pronoun $\mathrm{R}$ can establish a syntactic dependency with $\mathrm{N}$ only if $\mathrm{N}$ occupies R's binding domain (24).

(23) a. William thinks that ${ }_{\mathrm{BD}}$ Edith dislikes him].

b. * Edith thinks that ${ }_{\mathrm{BD}}$ William dislikes him $]$.

$(\mathrm{BD}=$ binding domain for him)

(24) a. * William thinks that ${ }_{\mathrm{BD}}$ Edith dislikes himself].

b. Edith thinks that ${ }_{\mathrm{BD}}$ William dislikes himself].

Interestingly, common and proper noun phrases, such as the red apple and London, can never be tails of non-gap dependencies, as (25) shows. In this example, the sentence is judged as unacceptable if she and Virginia refer to the same person. The sentence is only acceptable if she and Virginia refer to different people, in which case no dependency is established between the two phrases.

\section{(25) She regrets that Virginia hurt Joseph's feelings.}

When a nominal tail engages in such dependencies, it is referred to as bound. The three facts about nominal binding exemplified in (23) to (25) have endured because they are incredibly useful for diagnosing syntactic structure. For instance, if one wants to know the size of particular syntactic phrase P (i.e. whether it is as large as a binding domain), one can test to see how bound pronouns behave within P. Alternatively, if one wants to know if a particular hierarchical position A in a sentence c-commands another position $\mathrm{B}$, one can see if a nonlocal dependency between two co-referring proper nouns can be established using these positions. If it cannot, then A c-commands B.

It should be clear at this juncture that one can organize the discoveries discussed so far in this subsection such that they form an emerging typology of nonlocal syntactic dependencies. This typology is presented in diagrammatic form in (26). 
contains gap?

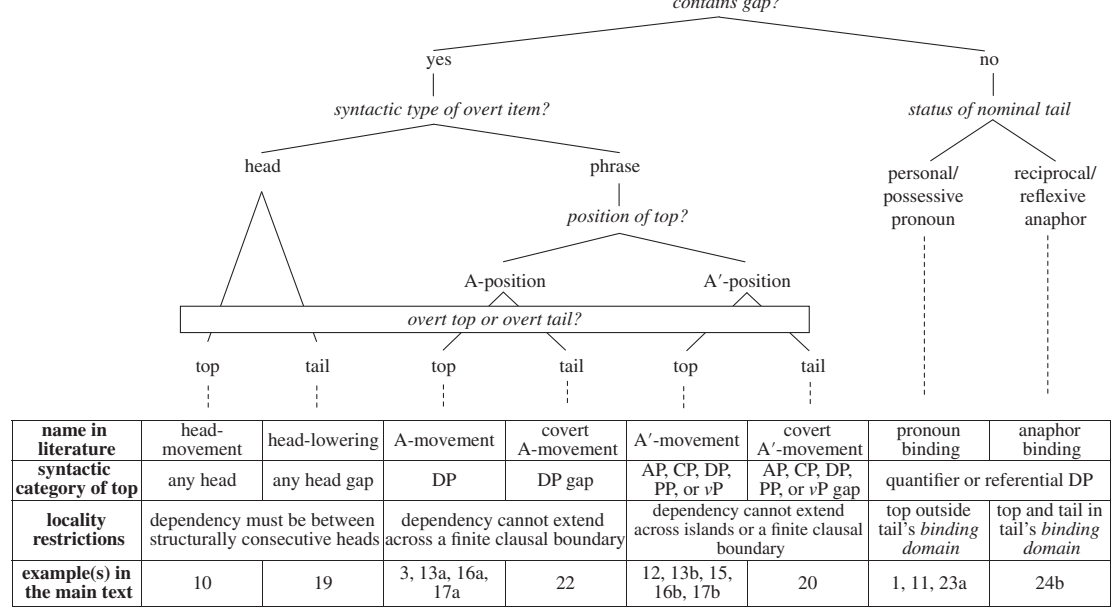


We must emphasize here that, although the table in (26) consolidates the preceding text in a clear and instructive way, it does not attempt to provide an exhaustive typology of the nonlocal dependencies uncovered by generative linguists over the last 60 years. The main reason for this is that the position of certain types of nonlocal dependencies within this table is still debated. For instance, it remains undecided whether the phenomenon of extraposition, which involves phrases appearing rightward of their canonical position (compare (27a) and $(27 \mathrm{~b}-\mathrm{c})$ ) and which was first documented by Rosenbaum (1967), involves a gap (27b) (as Ross 1967 and Baltin 1981 contend) or not (27c) (as Culicover and Rochemont 1990 and Haider 2010 argue).

(27) a. Someone that I don't know has left a message on your answer machine.

b. Someone $\Delta$ has left a message on your answer machine that I don't know.

c. Someone has left a message on your answer machine that I don't know.

This typology (or one similar to it) has endured because it represents the agreed-upon generalizations that form the bedrock for much recent generative linguistic research. This research has typically aimed to either (i) subsume a newly discovered or neglected nonlocal dependency under an established class or (ii) show that certain classes in the established typology are only superficially different, and that, at the correct level of analysis, they are indistinct.

In research that aims to fulfill (i), the discoveries that constitute (26) are used as diagnostic tools. Consider the phenomenon of scrambling (Ross 1967), which refers to the process that derives noncanonical word orders, typically within the same clause (compare (28a) and (28b), from Japanese).

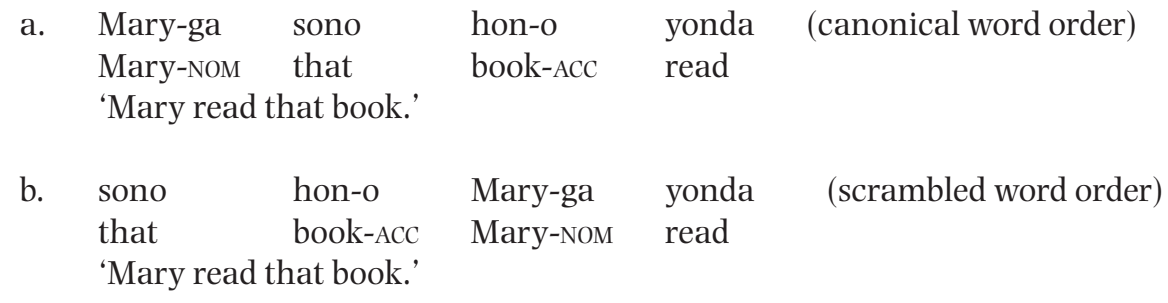

Recall that A- and $\mathrm{A}^{\prime}$-dependencies behave differently with respect to crossover and parasitic gaps (recall the discussion surrounding the examples in (16) to (18)). By using these facts and others as diagnostic tools - i.e. by observing how scrambling behaves with respect to these phenomena - linguists were able to determine whether scrambling is an A- or $\mathrm{A}^{\prime}$-dependency. It transpires that there are actually two forms of scrambling (A-scrambling and A'-scrambling) (Fanselow 1990; Mahajan 1990; Webelhuth 1992; see Karimi 2008 for an overview), an important discovery demonstrating that the same surface syntactic pattern - namely, noncanonical word-order - can arise from distinct grammatical processes.

In attempting to reduce the typology in (26) to a more fundamental picture, research that aims to fulfil (ii) frequently tackles the question of why natural language contains the seemingly different classes of nonlocal dependencies that it does. Chomsky's linguistic research from the mid-1970s onward has reductionist tendencies in this 
vein, and has been explicitly reductionist since 1995's Minimalist Program. A common target for this type of linguistic research is locality constraints. For instance, Chomsky (1977) famously proposed that the locality constraints on establishing an $\mathrm{A}^{\prime}$-dependency - namely, that an $\mathrm{A}^{\prime}$-dependency cannot extend across a syntactic island or two clausal boundaries - are reflections of one underlying locality constraint called Subjacency. According to conceptual framework behind Subjacency, certain phrases (the Tense Phrase and the Noun Phrase in English) are, by their nature, partial disruptors of $\mathrm{A}^{\prime}$-dependencies that extend across them. This idea has been retained in Subjacency's successor, the Phase Theory (Chomsky 2000, 2001a, 2001b), in which certain phrases (the Complementizer Phrase and the $v \mathrm{P}$ (as in (9)) are again considered to be inherent disruptors of nonlocal dependencies. In removing the notion of syntactic islands from syntactic theory, Subjacency and its successor Phase Theory in effect unite the locality conditions on A and A'-dependencies, with the ban on Improper Movement (see (18b)) yielding the apparent finite-clause-boundedness of A-dependencies.

\subsubsection{A Typology of Gaps}

When coupled with the fact that functional heads are often "empty" (see Section 4.3.1), the typology in (26) also underscores the fact that, at least according to most interpretations of fruitful generative inquiry, natural language contains many gaps. The ubiquity of gaps in natural language - not only as the tops and tails of nonlocal dependencies but also as independent items - has prompted extensive research into the precise status of gaps and whether all gaps have the same status. With regards to the former issue, generative linguists are divided as to whether gaps are linguistic items in their own right, akin to "silent" phrases, words, or morphemes, depending on the gap in question (this tradition starts with Chomsky 1973), or whether they are merely indications of the special grammatical or categorial status of the syntactic phrase in which the gap is found (this tradition took hold with Gazdar et al. 1985). With regards to the issue of whether all gaps have the same status, the picture is also unclear, with differences posited in earlier generative research being subject to reductivist reanalysis, especially within the current post-1995 Minimalist paradigm. However, many of differences between gaps posited in earlier research can nonetheless be classified as enduring discoveries, as few - if any - reductivist analyses of gaps enjoy universal acceptance.

Famously, different types of gaps have been implicated in explanations of the semantic and syntactic behavior of predicates that select infinitival clauses. Rosenbaum (1967) observed that, despite their superficial similarity, sentences such as (29) and (30) are inherently different in meaning. In (29), Kate is understood as the agent of helping Meghan event, but not of the seeming to help Meghan event (in fact, the latter event has no agent whatsoever). In (30), however, Kate is understood as the agent of both the helping Meghan and the promising to help Meghan event.

(29) Kate seems to help Meghan.

(30) Kate promises to help Meghan.

This difference in meaning suggests that seem does not assign an agentive thematic role to its subject Kate, whereas promise does. Because this is confirmed by various independent syntactic tests (see Landau 2013), Rosenbaum (1967), Postal (1974), and many researchers since them assume that this difference between seem- and 
promise-type predicates is reflected in syntactic structure. ${ }^{11}$ The example in (29) is analyzed as derived by a transformation called raising that "moves" Kate from the subject position in the embedded clause (i.e. immediately preceding to) to the subject position in the root clause (i.e. immediately preceding seems) (31). The gap in (31) is therefore a trace of the position that Kate occupied before raising occurs (see endnote 4).

(31) Kate seems $\boldsymbol{t}_{\text {Kate }}$ to help Meghan. (32) Kate seems PRO to help Meghan. (where $t_{\text {Kate }}$ is the trace of Kate's raising) (where PRO is silent pronoun interpreted as "Kate")

By contrast, Rosenbaum treated the gap in (30) as an unpronounced nominal (later analyzed as a silent pronoun called PRO; see Chomsky 1981 for a thorough treatment), which enters into a nonlocal dependency with Kate and is understood as co-referent with her, yet is not related to Kate through a derivational history (32). In the linguistic jargon, Kate controls the interpretation of PRO.

PRO and standard, pronounced nominals show a complementary syntactic distribution. However, many languages display silent pronouns that can occupy the same positions that pronounced pronouns can, such as the subject position of a finite clause (33). To distinguish them from PROs, these silent pronouns are referred to as "little" pros (Chomsky 1981). Proof that the "missing" subject in (33) is indeed instantiated syntactically by pro (rather than being merely pragmatically inferred) comes from the fact that it engages in a syntactic dependency with the verb for first-person singular agreement.

$$
\begin{aligned}
& \begin{array}{lll}
\Delta_{\text {pro }} & \text { sen-i } & \text { gör-dü-m } \\
& 2 \mathrm{sG}-\mathrm{ACC} & \text { see-PST-1SG }
\end{array} \\
& \text { "I saw you." }
\end{aligned}
$$

[Turkish]

Throughout this section, we have used the symbol $\Delta$ to represent gaps, which could give the impression that all gaps are atomic, and hence devoid of internal structure. Although some gaps are indeed atomic (e.g. null simplex syntactic heads, see Section 4.3.1), generative research has shown that many are nonatomic, and therefore have internal complexity. An instructive example comes from the domain of ellipsis. Ellipsis is a family-resemblance term in generative linguistics, whose archetype is post-auxiliary predicate ellipsis in English. This refers to sentences in which a predicate - often a verb phrase - is missing yet inferred (34). Evidence that the missing predicate is a syntactic phrase with internal structure comes from the discovery that these silent phrases can contain the tail of a nonlocal dependency (35) (see Haïk 1987 for detailed discussion). If the missing predicate were a simple, atomic syntactic element, then no nonlocal dependency would be established in (35) and the sentence would be unacceptable, contrary to observation.

(34) David should arrive on time and Fiona should $\Delta$, too.

(35) I know who will arrive on time and also who won't arrive on time $\Delta$.

(where strikethrough represents the silent, elliptic predicate) 
Beyond ellipsis, there is evidence that gaps in certain $\mathrm{A}^{\prime}$-dependencies also have internal structure. This evidence comes from the phenomenon of reconstruction, which was mentioned briefly in Section 4.3.2. Reconstruction describes situations in which the top member of an $\mathrm{A}^{\prime}$-dependency behaves as though it occupies the tail position of its dependency. Consider the second sentence in (36), in which the reference of her first PhD student is dependent on the reference of every professor (i.e. Professor Brown remembers Olivia, Professor Black remembers Davina, etc.). Recall from (1) that her must be c-commanded by every professor for this co-variant interpretation to be possible. On the surface, her first PhD student is not c-commanded by every professor in (36). However, this phrase is engaged in an $\mathrm{A}^{\prime}$-dependency with a gap that is c-commanded by every professor, and is interpreted as occupying this position.

(36) a. No professor is likely to remember her very first undergraduate student.

b. But her first PhD student, every professor will remember $\Delta$.

$\mathrm{A}^{\prime}$-dependency

Although reconstructed interpretations can arise from different sources (Lechner 1998), it is uncontested that many reconstructed interpretations come from the fact that the gap in certain $\mathrm{A}^{\prime}$-dependencies has internal structure, and is actually a verbatim yet silent copy of the A'-dependency's top member (37) (Chomsky 1995 [1993]). Thus, the existence of reconstructed interpretations reveals that many syntactic "gaps" are merely standard yet unpronounced syntactic phrases.

... but her first PhD student, every professor will remember her first $\mathrm{PhD}$ student.

\subsubsection{Section Summary}

By viewing generative syntactic research through the lens of nonlocal dependencies, we presented in this section approximately 35 enduring discoveries of generative syntax (depending on how one counts). Primarily, generative research has uncovered that (i) grammatical function is typically reflected in hierarchical structure, (ii) natural language is awash with nonlocal dependencies of various types, and (iii) there exist a variety of linguistic elements that contribute to meaning and participate in syntactic dependencies yet are not pronounced.

\subsection{Conclusion}

The foundation for contemporary generative syntactic research is a broad class of generalizations about natural language syntax that were (primarily) discovered between the late 1950s and the early 1980s and that (primarily) concern nonlocal syntactic dependencies and the hierarchical structure on which they are instantiated. These generalizations are "enduring" because they are cross-linguistically robust, they can be organized into typologies that encourage reductivist analysis, and they serve as useful diagnostic tools. The fact that generative syntax has uncovered such a large number of generalizations in such a short span of time (relative to the progress made in 
the centuries that preceded its inception) is directly attributable to its conceptual and methodological foundations, which were established by Noam Chomsky in his earliest work on language.

\section{Endnotes}

1 Our intended readership is broad, extending beyond generative linguists. For a more comprehensive list of the enduring discoveries of generative syntax that is aimed primarily at generative linguists, see D'Alessandro (2019).

2 Generativism has never denied that acceptability judgments are influenced by many factors demonstrably unrelated to grammaticality, such as processing costs and cultural norms. The name "acceptability judgment" (as opposed to "grammaticality judgment"), which originates with Chomsky (1965), explicitly acknowledges this fact. Generative linguists aim to control for these extraneous factors in their elicitation procedures, or alternatively take these confounds into consideration when developing their analyses.

3 For most of the generativist period, acceptability judgments have been collected using an informal methodology that does not meet the experimental standards expected in neighboring fields such as psychology (see Schütze and Sprouse 2013, 30 for details). Although it has attracted criticism (Edelman and Christiansen 2003, Ferreira 2005, Wasow and Arnold 2005, Featherston 2007, Gibson and Fedorenko 2010, 2013; see Hill 1961 for an early critique), recent research has demonstrated that, thanks to large effect-sizes, this method of collecting judgments is as reliable as "formal" collection methods, with convergence between the two ranging between 86\% to 99\% (Sprouse and Almeida 2012, 2013, 2017a, 2017b; Sprouse, Schütze and Almeida 2013, Schütze 2020).

4 Viewing transformations as descriptions of nonlocal dependencies came later and indirectly, via Chomsky's adoption from Hockett (1958) of deep versus surface structure in Chomsky 1964 and via his technical innovation of traces in Chomsky 1973. See Chomsky 1977 for a partial subsumption of traces under silent pronouns (or, more precisely, PRO) and Koster 1978 for an early argument for abandoning the notion that any nonlocal dependencies are established via the application of transformational rules.

5 The asterisk symbol is used to denote that an example sentence is judged by native speakers as unacceptable. In the absence of any observable confounding factors, this judgment is viewed as evidence that the sentence in question is also ungrammatical.

6 For the sake of simplicity, the phrase marker in (8) avoids representing the $\mathrm{X}^{\prime}$-levels characteristic of $X^{\prime}$-theory.

7 This is a crude description, based on a generalization that provoked Chomsky's (1977) theory of Subjacency (see the concluding paragraphs of Section 4.3.2). For a more contemporary perspective, in which many more "hidden" dependencies are postulated than are represented in the examples in (14) (and (18)), see the discussion following example (28) and the references provided there.

8 The idea that question phrases in wh-in-situ languages are tails in a top-gap A'-dependency was first advanced by Aoun, Hornstein, and Sportiche (1981). At first glance, it appears that the top-gap and tail-gap A'-dependencies that are utilized to form constituent questions across languages differ in their locality constraints, as the former appear to be establishable across island boundaries, unlike the latter (compare (i) below with (14) in the main text). Subsequent research has shown that this difference is only apparent. In island-obviating cases, the entire island (Nishigauchi 1986, Choe 1987, Pesetsky 1987) or a Q-morpheme associated with it (Cheng 1991, Hagstrom 1999, Cable 2010) is the tail of the dependency, not the question phrase contained within it.
(i) Ali
[ISLAND
kim gel-di
diye]
gülümse-di?
[Turkish]
Ali
who arrive-PST COMP smile-PST

'Who is it such that Ali smiled because s/he arrived?' 
9 These constraints form the Binding Theory. See Chomsky (1981) for an influential formulation.

10 Precisely how to define a binding domain has been a long-standing topic of debate. For a definition based solely on hierarchical syntactic structure, see Chomsky (1981). For a definition which considers hierarchical structure and linear order (in particular, precedence) see Langacker (1969), Lasnik (1976), and Bruening (2014). For definitions that define binding over functional relations such as obliqueness, which are only partly reflected in hierarchical structure, see Pollard and Sag (1994) and Bresnan (2001).

11 This assumption is not universally upheld. For instance, offshoots of mainstream generativism such as Head Driven Phrase Structure Grammar (Sag and Pollard 1991), Lexical Functional Grammar (Bresnan 1982), and Simpler Syntax (Culicover and Jackendoff 2005 ) maintain that the difference in argument-structure properties between seem- and promise-type predicates is not reflected in syntactic structure. In the generative literature, this idea originates with Bach (1977).

\section{References}

Abney, S. 1987. The English Noun Phrase in Its Sentential Aspect. PhD diss., MIT.

Adger, D., D. Harbour, and L. Watkins. 2009. Mirrors and Microparameters: Phrase Structure Beyond Free Word Order. Cambridge: Cambridge University Press.

Alexiadou, A., E. Anagnostopoulou, and M. Evereart. 2004. The Unaccusativity Puzzle: Explorations of the Syntax-Lexicon Interface. Oxford: Oxford University Press.

Aoun, J., N. Hornstein, and D. Sportiche. 1980. "Some Aspects of Wide Scope Quantification." Journal of Linguistic Research 1, 69-95.

Bach, E. 1977. "Review article on Postal, On Raising: One Rule of English Grammar and Its Theoretical Implications." Language 53, 621-54. DOI: 10.2307/413179

Baltin, M. 1981. "Strict bounding." In The Logical Problem of Language Acquisition, edited by C. L. Baker and J. McCarthy, 257-295. Cambridge, MA: MIT Press.

Barss, A. 2001. "Syntactic Reconstruction Effects." In The Handbook of Contemporary Syntactic Theory, edited by M. Baltin and C. Collins, 670-696. London: Blackwell. DOI:10.1002/9780470756416.ch21.

Bresnan, J. 1982. The Mental Representation of Grammatical Relations. Cambridge, MA: MIT Press.

Bresnan, J. 2001. Lexical-Functional Syntax. Oxford: Blackwell.

Bruening, B. 2014. “Precede-and-Command Revisited.” Language 90, 342-388. DOI: 10.1353/ lan.2014.0037.

Burzio, L. 1981. Intransitive Verbs and Italian Auxiliaries. PhD diss., MIT.

Cable, S. 2010. The Grammar of Q: Q-Particles, Wh-Movement and Pied-Piping. Oxford: Oxford University Press.

Cheng, L. L.-S. 1991. On the Typology of Wh-Questions. PhD diss., MIT.

Choe, Jae W. 1987. "LF Movement and Pied-Piping.” Linguistic Inquiry 18, 348-353.

Chomsky, N. 1955. Transformational Analysis. PhD diss., University of Pennsylvania.

Chomsky, N. 1957. Syntactic Structures. The Hague: Mouton.

Chomsky, N. 1958. "Linguistics, Logic, Psychology, and Computers." In Computer Programming and Artificial Intelligence, edited by J. W. Carr, 429-454. Ann Arbor, MI: Michigan University College of Engineering.

Chomsky, N. 1959. "Review of Skinner (1957).” Language 35, 26-58. DOI: 10.2307/411334.

Chomsky, N. 1964. "Current Issues in Linguistic Theory." In The Structure of Language, edited by J. A. Fodor and J. J. Katz, 50-118. Englewood Cliffs, NJ: Prentice-Hall. 
Chomsky, N. 1965. Aspects of the Theory of Syntax. Cambridge, MA: MIT Press.

Chomsky, N. 1970. "Remarks on Nominalization." In Readings in English Transformational Grammar, edited by R. Jacobs and P. Rosenbaum, 184-221. Waltham, MA: Blaisdell.

Chomsky, N. 1973. "Conditions on Transformations." In A Festschrift for Morris Halle, edited by S. R. Anderson and P. Kiparsky, 232-286. New York: Holt, Rinehart and Winston.

Chomsky, N. 1977. "On wh-movement.” In Formal Syntax, edited by P. W. Culicover, T. Wasow, and A. Akmajian, 71-133. New York: Academic Press.

Chomsky, N. 1981. Lectures on Government and Binding: The Pisa Lectures. Dordrecht: Foris.

Chomsky, N. 1986a. Knowledge of Language: Its Nature, Origin, and Use. New York: Praeger.

Chomsky, N. 1986b. Barriers. Cambridge, MA: MIT Press.

Chomsky, N. 1993. "A Minimalist Program for Linguistic Theory.” In The View from Building 20: Essays in Linguistics in Honor of Sylvain Bromberger, edited by K. L. Hale, and S. J. Keyser, 1-52. Cambridge, MA: MIT Press. Reprinted in Chomsky (1995a).

Chomsky, N. 1995b. The Minimalist Program. Cambridge, MA: MIT Press.

Chomsky, N. 2000. "Minimalist Inquiries: The framework." In Step by Step: Essays on Minimalist Syntax in Honor of Howard Lasnik, edited by R. Martin, D. Michaels and J. Uriagereka, 89-155. Cambridge, MA: MIT Press.

Chomsky, N. 2001a. "Derivation by Phase.” In Ken Hale: A Life in Language, edited by M. Kenstowicz, 1-50. Cambridge, MA: MIT Press.

Chomsky, N. 2001b. "Beyond Explanatory Adequacy." MIT Occasional Papers in Linguistics 20, $1-28$.

Chomsky, N. and M. Halle. 1968. The Sound Pattern of English. New York: Harper and Row.

Chung, S. 1994. "Wh-agreement and "Referentiality" in Chamorro." Linguistic Inquiry 25, 1-44.

Culicover, P. W. and M. J. Rochemont. 1990. "Extraposition and the Complement Principle." Linguistic Inquiry 21, 23-47.

Culicover, P. W. and R. Jackendoff. 2005. Simpler Syntax. Oxford: Oxford University Press.

D’Alessandro, R. 2019. “The Achievements of Generative Syntax: A time chart.” Catalan Journal of Linguistics [Special Issue: Generative Syntax. Questions, Crossroads, and Challenges], 7-26. DOI: https://doi.org/10.5565/rev/catjl.232.

Edelman, S. and M. Christiansen. 2003. "How Seriously Should We Take Minimalist Syntax?" Trends in Cognitive Sciences 7, 60-61. DOI: 10.1016/s1364-6613(02)00045-1.

Emonds, J. 1976. A Transformational Approach to English Syntax. New York: Academic Press.

Engdahl, E. 1983. "Parasitic Gaps." Linguistics and Philosophy 6, 5-34. DOI: $10.1007 / \mathrm{BF} 00868088$.

Fanselow, G. 1990. "Scrambling as NP Movement." In Scrambling and Barriers, edited by G. Grewendorf and W. Sternefeld, 113-140. Amsterdam: John Benjamins. DOI: 10.1075/la.5.07fan.

Featherston, S. 2007. "Data in Generative Grammar: The Stick and the Carrot.” Theoretical Linguistics 33, 269-318. DOI: 10.1515/TL.2007.020.

Felser, C. 2004. "Wh-copying, Phases, and Successive Cyclicity.” Lingua 114, 543- 574. DOI: 10.1016/S0024-3841(03)00054-8.

Ferreira, F. 2005. "Psycholinguistics, Formal Grammars, and Cognitive Science." The Linguistic Review 22, 365-380. DOI: 10.1515/tlir.2005.22.2-4.365.

Fukui, N. 1986. A Theory of Category Projection and Its Applications. PhD diss., MIT.

Gazdar, G., E. Klein, G. K. Pullum and I. A. Sag. 1985. Generalized Phrase Structure Grammar. Cambridge, MA: Harvard University Press. 
Gibson, E. and E. Fedorenko. 2010. "Weak Quantitative Standards in Linguistics Research.” Trends in Cognitive Sciences 14, 233-234. DOI: 10.1016/j.tics.2010.03.005.

Gibson, E. and E. Fedorenko. 2013. "The Need for Quantitative Methods in Syntax and Semantics Research.” Language and Cognitive Processes 28, 88-124. DOI: 10.1080/ 01690965.2010.515080.

Grimshaw, J. 2000. "Locality and Extended Projection." In Lexical Specification and Insertion, edited by P. Coopmans, M. Everaert, and J. Grimshaw, 115-133. Amsterdam: John Benjamins. DOI: 10.1075/cilt.197.07gri.

Hagstrom, P. 1998. Decomposing Questions. PhD diss., MIT.

Haider, H. 2010. The Syntax of German. Cambridge: Cambridge University Press.

Haïk, I. 1987. "Bound VPs that Need to Be." Linguistics and Philosophy 10, 503-530. DOI: $10.1007 / \mathrm{BF} 00628068$.

Hale, K. and S. J. Keyser. 1991. On the Syntax of Argument Structure. Lexicon Project Working Papers 34, Center for Cognitive Science, MIT.

Hale, K. and S. J. Keyser. 1993. "On Argument Structure and the Lexical Expression of Syntactic Relations." In The View from Building 20: Essays in Linguistics in Honor of Sylvain Bromberger, edited by K. Hale and S. J. Keyser, 59-109. Cambridge, MA: MIT Press.

Harizanov, B. and V. Gribanova. 2019. "Whither head movement?" Natural Language and Linguistic Theory 37, 461-522. DOI: 10.1007/s11049-018-9420-5.

Harley, H. 2013. "Diagnosing Head Movement." In Diagnosing Syntax, edited by L. Cheng and N. Corver, 112-119. Oxford: Oxford University Press. DOI: 10.1093/ acprof:oso/9780199602490.003.0006.

Harris, Z. S. 1952. “Discourse Analysis.” Language 28, 1-30. DOI: 10.2307/409987.

Harris, Z. S. 1957. "Co-occurrence and Transformation in Linguistic Structure.” Language 33, 283-340. DOI: $10.2307 / 41115$.

Hiemstra, I. 1986. "Some Aspects of Wh-questions in Frisian." Nowele 8, 97-110. DOI: 10.1075/nowele.8.06hie.

Hill, A. A. 1961. “Grammaticality.” Word 17, 1-10. DOI: 10.1080/00437956.1961.11659742. Hockett, C. F. 1958. A Course in Modern Linguistics. New York: The Macmillan Company.

Jackendoff, R. 1977. X'-Syntax: A Study of Phrase Structure. Cambridge, MA: MIT Press

Jackendoff, R. 2002. Foundations of Language: Brain, Meaning, Grammar, Evolution. Oxford: Oxford University Press. DOI: 10.1093/acprof:oso/9780198270126.001.0001.

Karimi, S. 2008. "Scrambling." Language and Linguistics Compass 2/6, 1271-1293. DOI: 10.1111/j.1749-818X.2008.00095.x.

Klima, E. 1964. “Negation in English.” In The Structure of Language, edited by J. A. Fodor and J. J. Katz, 246-323. Englewood Cliffs, NJ: Prentice-Hall.

Koster, J. 1978. “Conditions, Empty Nodes, and Markedness.” Linguistic Inquiry 9, 551- 593.

Landau, I. 2013. Control in Generative Grammar: A Research Companion. Cambridge: Cambridge University Press.

Langacker, R. 1969. "On Pronominalization and the Chain of Command." In Modern Studies in English: Readings in Transformational Grammar, edited by D. Reibel and S. Schane, 160-186. Englewood Cliffs, NJ: Prentice-Hall.

Larson, R. 1988. "On the Double Object Construction.” Linguistic Inquiry 19, 335-392.

Lasnik, H. 1976. "Remarks on Coreference." Linguistic Analysis 2, 1-22. DOI: 10.1007/ 978-94-009-2542-7_4. 
Lechner, W. 1998. "Two Kinds of Reconstruction.” Studia Linguistica 52, 276-310. DOI: 10.1111/1467-9582.00037.

Mahajan, A. 1990. The A/A' Distinction and Movement Theory. PhD diss., MIT.

May, R. 1977. The Grammar of Quantification. PhD diss., MIT.

McCloskey, J. 2001. "The Morphosyntax of WH-extraction in Irish.” Journal of Linguistics 37, 67-100. DOI: 10.1017/S0022226701008775.

McDaniel, D. 1989. "Partial and Multiple Wh-movement.” Natural Language and Linguistic Theory 7, 565-604. DOI: 10.1007/BF00205158.

Nishigauchi, T. 1986. Quantification in Syntax. PhD diss., University of Massachusetts Amherst.

Perlmutter, D. 1978. "Impersonal Passives and the Unaccusative Hypothesis." In Proceedings of the Fourth Annual Meeting of the Berkeley Linguistic Society, edited by J. Jaeger et al., 157-189. Berkeley, CA: University of California, Berkeley.

Pesetsky, D. 1987. "Wh-in-situ: Movement and Unselective Binding." In The Representation of (In)definiteness, edited by E. Reuland and A. ter Meulen, 98-129. Cambridge, MA: MIT Press.

Pollard, C. J. and I. A. Sag. 1994. Head-driven Phrase Structure Grammar. Chicago, IL: University of Chicago Press.

Postal, P. 1971. Cross-over Phenomena. New York: Holt, Rinehart and Winston.

Postal, P. 1974. On Raising: One Rule of English grammar and Its Theoretical Implications. Cambridge, MA: MIT Press.

Potsdam, E. and M. Polinsky. 2012. "Backward Raising.” Syntax 15, 75-108. DOI: 10.1111/ j.1467-9612.2011.00158.x.

Reinhart, T. 1976. The Syntactic Domain of Anaphora. PhD diss., MIT.

Riemsdijk, H. van and E. Williams. 1981. "NP-structure.” The Linguistic Review 1, 171-217. DOI: 10.1515/tlir.1981.1.2.171.

Rosenbaum, P. 1967. The Grammar of English Predicate Complement Constructions. Cambridge, MA: MIT Press.

Ross, J. R. 1967. Constraints on Variables in Syntax. PhD diss., MIT.

Sag, I. A. and C. J. Pollard. 1991. “An Integrated Theory of Complement Control.” Language 67, 63-113. DOI: $10.2307 / 415539$.

Schütze, C. T. 2020. "Acceptability Ratings Cannot Be Taken at Face Value.” In Linguistic Intuitions, edited by S. Schindler, A. Drozdzowicz, and K. Brøcker 189-214. Oxford: Oxford University Press.

Schütze, C. T. and J. Sprouse. 2013. "Judgment Data.” In Research Methods in Linguistics, edited by R. J. Podesva and D. Sharma, 22-50. Cambridge: Cambridge University Press.

Speas, M. 1986. Adjunctions and Projections in Syntax. PhD diss., MIT.

Sprouse, J. and D. Almeida. 2012. "Assessing the Reliability of Textbook Data in Syntax: Adger's Core Syntax.” Journal of Linguistics 48, 609-652. DOI: 10.1017/S0022226712000011.

Sprouse, J. and D. Almeida 2013. "The Empirical Status of Data in Syntax: A reply to Gibson and Fedorenko." Language and Cognitive Processes 28, 222-228. DOI: 10.1080/ 01690965.2012.703782.

Sprouse, J. and D. Almeida. 2017a. "Design Sensitivity and Statistical Power in Acceptability Judgment Experiments." Glossa: A Journal of General Linguistics 2 (1), e14. DOI: 10.5334/gjgl.236.

Sprouse, J. and D. Almeida. 2017b. "Setting the Empirical Record Straight: Acceptability Judgments appear to be Reliable, Robust, and Replicable." Behavioral and Brain Sciences 40, e311. DOI: 10.1017/S0140525X17000590. 
Sprouse, J., C. T. Schütze and D. Almeida. 2013. "A Comparison of Informal and Formal Acceptability Judgments Using a Random Sample from Linguistic Inquiry 2001-2010.” Lingua 134, 219-248. DOI: 10.1016/j.lingua.2013.07.002.

Travis, L. 1984. Parameters and Effects of Word Order Variation. PhD diss., MIT.

Wasow, T. and J. Arnold. 2005. "Intuitions in Linguistic Argumentation." Lingua 115, 1481-1496. DOI: 10.1016/j.lingua.2004.07.001.

Webelhuth, G. 1992. Principles and Parameters of Syntactic Saturation. Oxford: Oxford University Press. 